Mazwi, N., Seremani, B., Kaseke, T., Lungu, C.

PSYCHO-SOCIAL EXPERIENCES OF YOUTHS DURING THE COVID-19 LOCKDOWN: INSIGHTS FROM HARARE,

ZIMBABWE

\title{
PSYCHO-SOCIAL EXPERIENCES OF YOUTHS DURING THE COVID-19 LOCKDOWN: INSIGHTS FROM HARARE, ZIMBABWE
}

\author{
Nicola Mazwi \\ Great Zimbabwe University, Department of Psychology, Harare, Zimbabwe \\ nicolamazwi49@gmail.com \\ Bongani Seremani \\ Great Zimbabwe University, Department of Psychology, Harare, Zimbabwe \\ bongani.seremani@gmail.com \\ Tsungai Kaseke \\ Great Zimbabwe University, Department of Psychology, Harare, Zimbabwe \\ tsungiekas@gmai.com \\ Clemencia Lungu \\ Great Zimbabwe University, Department of Psychology, Harare, Zimbabwe \\ rumbeelungu@gmail.com
}

\begin{abstract}
The COVID-19 pandemic that started in Wuhan, Hubei province in China in December 2019 has brought about varied psycho-social experiences to youths during the COVID-19 lockdown period. World Health Organisation warned that the coronavirus and the restrictive measures around it would have negative effects on people's mental health and well-being. Current scientific literature reveals that in China, UK and Spain COVID-19 outbreak resulted in symptoms leading to psychological disorders while in Africa the 2014 Ebola outbreak resulted in social and economic breakdowns in people's livelihoods. This qualitative study made use of document analysis as a research design. WhatsApp messages were analysed using thematic analysis. The study sought to explore how youths in Harare, Zimbabwe responded to the lockdown and ways in which the lives of the youths were psychologically and socially affected. Research questions were on; how youths in Harare responded to the lockdown; how the lockdown affected the youths; in what ways the lockdown affected psychological lives of the youths and what can be done in future in order to improve the lives of youths during pandemics. The study revealed that some youths of Harare presented psychological conditions leading to PTSD symptoms such as stress, confusion, anger, anxiety and depression while some embraced COVID-19 Lockdown as it improved family and social ties. It was also noted that youths should be able to access psychological services during epidemics in order to avert surges in mental health illnesses emanating from national lockdowns.
\end{abstract}

Keywords: Lockdown, COVID-19, Psycho-social, Youths 


\section{INTRODUCTION}

The COVID-19 is an on-going pandemic of coronavirus disease caused by severe acute respiratory syndrome. The World Health Organisation declared the outbreak to be a Public Health Emergency of International Concern on 30 January 2020. On March 11, 2020 the WHO declared COVID-19 a global pandemic (WHO, 2020). A pandemic is a disease prevalent over the whole country or the world. Several countries worldwide were encouraged to introduce social distancing in the form of national lockdown which was employed as a preventative measure to delay and mitigate the transmission of the virus and to reduce its impact on the population on national healthcare systems. The Zimbabwe government announced on March 27, 2020 that there was going to be a nationwide total lockdown for 21 days starting on March 30. In any epidemic, it is common for individuals to experience psychological and social problems at both individual and community levels. Common responses of people affected (both directly and indirectly) might include: fear of losing livelihoods, not being able to work during isolation, fear of being dismissed from work, fear of being separated from loved ones, feelings of hopelessness, boredom, loneliness and depression due to being isolated (IFRC, 2020). Social and psychological reactions may differ according to nations, its impact, culture, community, social links and support structures during this COVID-19 epidemic. Most researches that have been carried out so far were targeting the psychological impacts of people under quarantine, frontline health workers, the elderly population with respiratory conditions, and very few researches have looked at the impact of lockdown on the healthy population especially the active members of community, the youth. There are many assumptions relating to negative impact of social isolation such as in disruptions in routines, communication, social life as well as measures that promote autonomy like choice in daily activities which can all lead to psychological instability (New Zealand Ministry of Health, 2009). Authors of this article, anticipated that the outbreak of COVID-19 lockdown would have psychosocial effects on the youths especially in a country with high rates of informally employed people who rely on face to face business and personal interactions. In order to get an in-depth analysis of the state of affairs among the youth in Harare, participants were interviewed using social media platforms for communication and participants had to respond to interview questions on their understanding of the lockdown and how their lives had changed during the lockdown. It was also of great importance to find out from the youth if they were challenges and successes in maintaining social links and ways that can help them adapt effectively to the changes. This paper will provide substantial contributions that will assist in mapping a framework for the need for mental health psychosocial services for youth under lockdown during and after the COVID-19 pandemic in a country like Zimbabwe. 


\section{LITERATURE REVIEW}

Since the beginning of the outbreak in China, COVID-19 has spread subsequently to the rest of the world causing an on-going pandemic (Rosario et al., 2020). National lockdowns have been employed by most countries as a social distancing measure to reduce and mitigate the spread of the virus. The WHO warned that coronavirus crisis and the restrictive measures can have a negative impact on people's mental health and well-being. (Brooks et al., 2020) informs that the psychological impact of quarantine is wide-ranging, substantial and can be long lasting. Taking into consideration the current lockdown situation, it has disrupted social support networks at a time when they are most needed by closure of schools and work, places of worship, altering the normal daily activities and restricting social physical interactions.

In China, one of the first studies conducted to investigate the initial psychological responses of the general public on the COVID-19 outbreak, revealed that $53.8 \%$ of respondents rated the psychological impact as moderate or severe, $16.5 \%$ reported moderate to severe depressive symptoms, $28.8 \%$ reported moderate to severe anxiety and stress (Wang et al., 2020). A review published recently by Lancet (2020) which studied the psychological impact of quarantine in the UK found proof of a range of psychological conditions from PTSD symptoms to confusion, anger, depression, stress, insomnia and emotional exhaustion (Brooks et al., 2020). In Spain, the pandemic is raising the anxiety levels due to the affective and cognitive alterations people are going through, (Rosario et al., 2020). The isolation and anxiety in lockdown era can drive an escalating nervousness among people which can trigger mental health related disorders.

Students can experience higher levels of anxiety, stress and depression due to the uncertainty and potential negative impact on academic progression especially in universities. In the China report, respondents (93.5\%) used the internet as their main information route of transmission (Wang et al., 2020) as young people are more receptive towards smartphone applications and online platforms could also provide a support network for those spending most of their time at home during the epidemic. Health authorities were considering online-smartphone based psychoeducation and psychological interventions (CBT- Cognitive Behavioural therapy) to reduce risk of transmission by face to face therapy (Wang et al., 2020).

While lockdown can be frustrating, it is vital and African countries have also employed strict social distancing measures in the form of total national lockdowns despite the high economic and social impact this will have on the continent. Epidemic such as the COVID-19 can result in reduced quality of life, economic productivity and social system breakdown as evident in the 2014 Ebola epidemic (Van Bortel et al, 2016). Psychosocial care after the Ebola epidemic has been insufficient due to lack of resources, overburdened health systems and a lack of knowledge about supporting psychosocial needs (Van Bortel et al., 2016). Therefore, during the COVID-19 pandemic it is imperative to understand how the populations 
will cope with such a major epidemic as it increases feelings of uncertainty, unrest, loneliness and stress resulting in an increase in mental health psychosocial services that are easily accessible to communities. Experiences from countries affected early on like China and Italy have shown that it is better to be over prepared than not to prepare at all (Cheng et al., 2020). The Zimbabwe government announced on March 27,2020 that there was going to be a nationwide total lockdown for 21 days starting on March 30 , as a social distancing measure to prevent and mitigate the spread of COVID-19. The psychosocial effects in China might not be similar to other countries like Zimbabwe and there is need for adaptation to fit the new context (including adaptations to culture, language, health, economic and social systems etc). Social distancing has proven to be effective in countries such as China where they have employed online smartphone based communication (Wang et al., 2020). Therefore, there is need to investigate how people are coping with lockdown restrictions in a country like Zimbabwe where youth (ages 15-35 years) make up $35.7 \%$ of the total population (ZIMSTAT, 2014) during the COVID-19 epidemic.

\section{METHODOLOGY}

The research employed the use of Phenomenology research approach. It is used to get information that cannot be quantified and to get a deep understanding of people's feeling, attitudes, personalities and behaviour towards the COVID-19 lockdown. The research used qualitative approach specifically the document analysis research design. According to (Bowen 2009), document analysis is a form of qualitative research in which a researcher interprets documents to give voice and meaning around an assessment topic. It is a social research tool in its own right, and is an invaluable part of most schemes of triangulation, the combination of methodologies in the study of the same phenomenon, (Bowen 2009). The particular research design was chosen as it the best way of gathering data under the specific conditions (social distancing) of the lockdown.

\subsection{Data collection procedure}

Data was collected through interviews with structured questions in which participant answered using word documents through WhatsApp and Facebook. The research employed the use of interactions with participants done via text and audios on social media platforms of WhatsApp and Facebook. There would be correspondence between the researchers and the participants through these social media platforms. Responses were recorded in a document form. 


\subsection{Population}

The population of the study consisted of youth of Harare. The research focused on 9 different youths aged between 19 and 35 in the Harare Suburb who were selected purposefully. The sample of participants selected was sufficient enough to present research results, as qualitative research design uses a small group of participants to get deep understanding.

\subsection{Sample and sampling strategy}

Participants were selected using purposive sampling strategy, that is, the researcher selected participants that where accessible and had the relevant information needed by the researchers. The research conveniently focused on both individuals whose psycho-social experiences where either positive or negative.

Thematic data analysis was used to analyze data and themes and sub themes were drawn from the research questions and the analysis of the responses from the participants.

Research questions used when collecting data addressed the following concepts:

- How have the youths in Harare responded to the lockdown?

- How has the lockdown affected social lives of youths in Harare?

- In what ways has the lockdown affected psychological lives of youths in Harare?

- What can be done in future to improve the lives of youth in similar situations?

\section{RESULTS AND DISCUSSION}

\subsection{COVID19 Lockdown and social lives of youths}

The study revealed that youths were affected socially by the lockdown. The twenty-one (21) days lockdown commenced on 31 March 2020 to last until 20 April 2020. The COVID-19 Lockdown was a way of mitigating the spread of the corona virus and it entailed that people were restricted to their homes and only left their homes if it was very necessary. The Government of Zimbabwe gave a directive that all companies except for pharmaceutical shops, grocery shops and any key essential service providers were to be closed down and also social gatherings were prohibited during the lockdown period. Funerals were restricted to a maximum of fifty mourners. This directive entailed that pubs, churches, social clubs, sports clubs, gymnasiums and any other social amenities were closed down. Social visits or meetings were also prohibited as people were restricted to their homes. The only movement that was allowed was for people who were engaged in essential services and they carried around letters of employment to prove their services are essential during the lockdown period. 


\section{Mazwi, N., Seremani, B., Kaseke, T., Lungu, C. \\ PSYCHO-SOCIAL EXPERIENCES OF YOUTHS DURING THE COVID-19 LOCKDOWN: INSIGHTS FROM HARARE, ZIMBABWE}

The restriction on movements and closing of social amenities brought different emotions to the youths such as anger, frustration, sadness, panic, depressive moods, overwhelming feelings, anxiety and feelings of oppression. Participant 5 expressed, "My social life has been affected greatly because I am forced to spend time watching the television and all the international news is on corona virus updates and increase in deaths and number of affected people. In other news Zimbabwe is said to have no test kits and equipment to deal with the virus." Furthermore, he stated, "This is depressing as one wonders whether in Zimbabwe we will survive when the cases of infected numbers increase." Participant 2 highlighted, "I am a social person, I love going to church, gym and doing activities with friends. The lockdown has taken away social interactions with friends and family, I feel oppressed, anxious, angry and discontent it's frustrating." He reiterates, "A human being is a social animal that needs human contact in interaction and being locked down can be overwhelming."

Feelings of anger, frustration, sadness and being overwhelmed due to freedom deprivation where evidenced in the research as Participant 3 echoed, "The lockdown has taken away social interactions with family and friends as it has minimised social activities such as attending gym, shopping and going to church. It gives a sad experience and overwhelming at the same time because my freedom has been taken away. I feel oppressed, anxious, and angry and discontent, it's frustrating. "

Youths are panicking due to uncertainty and inadequate information that is channeled through media as Participant 5 expressed, "I am in a panic mode because I feel we are not getting the correct information and the media is suppressing the figures. So if I just have a cough I think maybe this is Covid19 so I am operating in a panic mode because of this Covid19 Lockdown." There is sadness, feelings of low emotions that the youths are experiencing as stressed by Participant 2, "I am a sportsman and always want to be out and about with my team mates so this has affected me badly and I feel disheartened, sad and low during this lockdown." He further indicated "Nothing can replace what I had in the outdoor world even if I do workouts and play games on my mobile phone."

Covid-19 News updates around the world are affecting people negatively while emotions are stirred up as Participant 7 stated, "What only makes me emotional are the number of deaths that are being recorded in other countries every single day and I pray and hope the virus finds a cure soon." Feelings of anger due to the sudden hike of airtime by vendors are experienced as Participant 5 highlights, "Data charges are too high and airtime is scarce during this lockdown period and it is depressing to see airtime vendors taking advantage of the situation and selling airtime at exorbitant rates and one feels like hitting the airtime vendor." Furthermore, he expressed, "Mobile phone networks have been unstable during this lockdown and when messages are not delivered in the middle of playing a game with friends I feel like throwing my phone down and breaking it because of frustration." 
These sentiments reveal the level of psychological problems such as anxieties, sadness, anger, depressed feelings and panic that has been brought about by COVID-19 Lockdown. Such psychological effects of the lockdown are in line with the WHO warning that coronavirus crisis and the restrictive measures can have a negative impact on people's mental health and well-being (Zhang and Ma, 2020). Considering that this study was carried out during the first ten days of the twenty-one days of lockdown and even when the pandemic reaches high levels of infected numbers. This study also concurs with the study on psychological impact of quarantine in the UK by Lancet showing psychological conditions from PTSD symptoms such as anger, confusion, depression, stress, emotional exhaustion and insomnia especially in young people that are used to social freedom (Brooks et.al, 2020). The lockdown can trigger mental health disorders such as depression, panic disorder and post-traumatic stress disorder.

\subsection{Social media during the COVID-19 lockdown}

The COVID-19 lockdown has confined everyone to their homes, no work for most of the people and no social events for everyone in order to minimize the spread of the corona virus through social distancing. The COVID-19 lockdown has pushed the youth and basically everyone to be active on social media platforms such as Facebook, WhatsApp, Twitter and Instagram to mention only a few. Social media platforms have been excessively used to communicate with fellow peers, workmates and friends as people aren't allowed to meet or rather go outside their homes. In an attempt to try and maintain their social lives, the youth have been faced by both positive and negative psychological effects of the social media. Positively, as noted by Participant 6, "the COVID-19 lockdown has brought me closer to my friends that are on video chat and social media that are not closer to me always", thus the participant rather sees the lockdown as an opportunity to get closer to her friends that are outside of the country as she now has more time to be communication with them using different social media platforms such as WhatsApp video calls and hence a positive psychological aspect on some youths' social lives as the lockdown isn't affecting their social lives but rather enabling it and creating strong friendship bonds.

In addition, Participant 8 noted that, "everyone in my social life is on social media so there been no challenges in communicating", this shows that, some youth weren't affected in any way with communication as they are used to communicating with their peers and friends on different social media platforms and hence minimal psychological effects of maintaining some of the youth's social lives during the COVID-19 lockdown on social media platforms as they are used to doing so.

Most people have been forced during the COVID-19 lockdown to use Social media as a basic way of communicating with friends and fellow peers, workmates and social media and basically internet has been also used as a means for learning, this has guaranteed that almost, most people are glued to their 


\section{Mazwi, N., Seremani, B., Kaseke, T., Lungu, C. \\ PSYCHO-SOCIAL EXPERIENCES OF YOUTHS DURING THE COVID-19 LOCKDOWN: INSIGHTS FROM HARARE, ZIMBABWE}

phones and laptops for different reasons, this has exposed people to different social media platforms where negative messages have been circulating about the corona virus and most people are now addicted to their phones and social media as noted by participant 5 who noted that, "emotionally it affects because this lockdown has made us glued to T.V and WhatsApp to be updated on current news of the virus, so seeing the increase of cases, number of deaths in other countries is really disturbing and some news saying Zimbabwe we got no test kits and equipment to deal with the virus affects emotionally..." youths have been recorded to be the most active on social media and hence the most affected emotionally as social media doesn't discriminate information, whether true or false, information found on social media platforms can be damaging and have a negative impact on youths' psychological wellbeing, as expressed by the participant 3 who is affected emotionally by the negative information on social media and Television and expressed great concern on the information on the social media that Zimbabwe is not equipped enough to deal with virus and thus affecting the youth emotionally and hence their overall psychological wellbeing, this is supported by (Brooks et al 2020), who states that, the COVID-19 has had psychological impacts such as emotional exhaustion on the young people that are used to social freedom.

Youth favor to communicate through human contact rather than through social media platforms as this ensures the emotional involvement in a conversation or subject, however due to the COVID-19 lockdown, people have been confined in their homes and have resorted to communicating through social media platforms. In an attempted to maintain communication and social lives, the youth have resorted to social media, which has its own challenges as highlighted by Participant 3 who states that, "the greatest challenge with using WhatsApp is that, there is no human interaction as it is all virtual yet at times essential to see a person to communicate effectively". This proves the limits of social media as a means of communicating and how it affects the youth trying to maintain their social lives as facing these challenges affects them psychologically as communication lacks human contact and hence rendered emotion less and thus disrupting the social life norm.

The youth recognized social media platforms such as WhatsApp, Facebook, twitter and Instagram as their basic means of communication during the COVID-19 lockdown, these social media platforms are on the internet and hence require data for one to be able to use them, $75 \%$ of the youth faced network problems and some didn't have the money to buy the data as noted by participant $3, \ldots$ have mostly used WhatsApp as means of communication...the cost of such communication is high as it means frequently purchasing data", Participant 4 also posits that "money to buy airtime and data to go on the internet is now depleting faster since I use work internet to perform any tasks online and the money has not been budgeted for". 
Mazwi, N., Seremani, B., Kaseke, T., Lungu, C.

PSYCHO-SOCIAL EXPERIENCES OF YOUTHS DURING THE COVID-19 LOCKDOWN: INSIGHTS FROM HARARE,

ZIMBABWE

Participant 2 stated that "social media has done much of the assistance in terms of communication as well as other digital platforms and the main challenge has been the prices of goods and services as most youth are not able to purchase new gargets to use for communication as well as afford to buy data to be able to go online..."

Participant 6 stated that "the main challenge is data prices which are too high, the bundles usually depletes at a crucial time where sometimes I would really need my friends at the moment. Airtime due to the lockdown is very scarce and what usually depress is that if you find it the seller for a $\$ 5$ netone recharge card he needs $\$ 7$ then you have this aaaaarrrrrgh feeling that you cannot really explain and you feel like hitting him or her". This shows how the youth are being affected economically and psychologically by the COVID-19 lockdown when they are trying to maintain their social lives through communicating via the social media which has unforeseeable challenges such as expensive data and low network which makes communication hard when it's needed the most.

\subsection{COVID-19 and Psychological lives of youths}

From the study carried out, there is evidence that introverts and extroverts react differently to the Lockdown. Introverts have adjusted well as they are used to the solitude and personal space as compared to the extroverts. 5 of the 9 participants interviewed were introverts and they were males in the age range of 30-35. All of the introvert participants were family people who are married and to them, the lockdown was a good way of family bonding hence the isolation did not affect them much and this view is supported by (Suedfeld and Steel, 2000) on how people who share their homes with loved ones cope better. The extrovert participants were 2 females and 1 male in the age range of 24-29. Only 1 participant a female aged 29 claimed to be both introvert and extrovert depending on the situation. All of the people interviewed are working class both formal and informal workers.

Differences in personalities emerge early in life and they stabilize as one grows older. From the study, age and responsibilities in life play a contributing factor to how one reacts to the lockdown. For example, participant 6, a female aged 29 said, "a friend had just given birth, I haven't seen the new bundle of joy, it's insane." This shows that she was feeling disappointed with not being able to celebrate with her friend on the coming of the new baby. This highlights how values differ according to age and responsibilities as she is more mature. Participant 3 a female aged 24 said, "As a social animal a human needs human contact and a lack of that can be overwhelming negatively." Youth in their 20s they are outgoing as they do not have many responsibilities but as one gets to their 30 s, they are now trying to settle down and responsibilities increase as some may now have families and children to take care of. 
Research has however revealed that people who are emotionally stable, self-reliant, autonomous, goaloriented, friendly, patient and open tend to cope better in conditions of extreme isolation (Suedfeld and Steel, 2000), Introverts find isolation easier to cope with as their motivation and mood is elevated from within so they are not pressured to seek out social pleasure. For example, participant 2 is an introvert and they responded that, "the lockdown affected their schedule of soccer matches as they now have to watch repeat matches." Some introverts saw this lockdown period as an opportunity to rest from their busy work schedules. Extroverts on the other hand are struggling as they are finding it difficult to cope as most of their lives is spent outdoors networking and making money. Participant 5 who is informally employed and makes income through social events stressed on "how lockdown has taken a heavy toll as he is forced to be unproductive and depend on mobile data for social networking which is expensive." Extroverts showed some frustration and claimed that indoor activities were boring.

However, both introverts and extroverts understood the importance of the lockdown in mitigating the spread of the COVID-19 virus. They all had one comment in common which could be contributing factor to their reaction to the lockdown which is how mobile data is expensive and this affects social networking or even accessing online information.

\subsection{Positive psychological effects of the COVID-19 lockdown on youths}

The COVID-19 pandemic lockdown has had positive effects on different youths depending on how an individual reacts to the lockdown. The lockdown dictates that, people are supposed to stay inside their homes and do not go outside, schools, public places such as restaurants have been closed, most business have been closed temporarily and even in streets people aren't allowed. This has left most cities and countries under the COVID-19 lockdown ghost's town, this has been done in an attempt to stop the spread of the virus through social distancing. In Zimbabwe, the lockdown has been received well and almost all the people are abiding with the COVID-19 rule, this means that, people are not going out of their houses except and only when necessary.

The COVID-19 lockdown has had positive psychological impacts on youth's social lives, as respondents noted that, as much as, there is a world pandemic, the lockdown has had positive effects in their social lives, especially the youths that are working. Being confined at home for the proposed 21 days COVID19 lockdown has managed to bring families closer and subsequently creating happy moods and feelings among families as they have managed to spend time together as families, as noted by participant 5 who posits that "my social life has been affected both positive and negative, the positive side is as an extrovert I am always out and about, so the lockdown has given me the chance to have time with my family". This shows how the COVID-19 lockdown has had a positive impact on people's lives as the lockdown has managed to keep youths inside their homes and closer to their families especially the 
youths that are extroverts and rarely had time to socialize and interact with their families but now they have the chance to and in a fun way be closer to their families, as participant 5 noted that, "as a family we have resorted to playing cards and different games as a family, helping each other to stay fit by exercising and watching T.V together as a family, this had greatly created a bond between us". This clearly proves the fact that, the lockdown has had positive effects on youth's social lives especially youth's that wished they always had more time with their families.

More so, Participant 8 noted that, "the COVID-19 lockdown hasn't affected me much as Im usually indoors", most youths that aren't working spend time at home, thus the lockdown hasn't affected them psychologically but rather to them, the COVID-19 lockdown isn't a hindrance on their social lives and hence they have accepted the lockdown. Participant 3 expressed that, "emotionally, I have taken time to reset from the hustles and bustles of the world. This means I am more focused on my needs and plans for the future..." thus some youths have taken the time provided by the COVID-19 lockdown to reflect on themselves and grow emotionally and hence a positive aspect on their psychological wellbeing as a whole. Due to busy schedules of maintaining work life and social lives, most youth have difficulties in getting time for themselves to deal with their life stressors and to basically take a break and just think, thus the lock down has come as a blessing in disguise as the youth have taken the time to rest and relax as they are forcefully under a well needed lockdown protecting people from the corona virus.

\subsection{Challenges in communication during the COVID-19 Lockdown}

As much as many of the participants enjoy human interaction, they also understand that they are living in a digital age, and have accepted that. However, the participants are facing challenges that are beyond their control in maintaining virtual communication. Three major challenges were highlighted, these being lack of human contact, expensive data tariff charges, and network challenges.

Only participants 1 and 8 did not face challenges. Participant 1 said "I don't have challenges because there is electricity at home all day". Participant 8 said "I have no challenges with communication since everyone I speak to is also on social media."

Participants 7 and 3 said to be struggling with the lack of human interaction. Participant 3 states that "the greatest challenge is not having human interaction...at times for effective communication it is essential to see a person to communicate." Participant 7 alluded that "no physical contact or interactions" was their greatest challenge.

Participants 2, 3, 4, 5 mentioned that purchasing data and airtime is expensive. Participant 2 stated that "some friends are not on social media and calling them is a challenge since it is expensive." Participant 
3 added that "constant communication is now more expensive because it means you are constantly purchasing data." Due to the price hikes it has made it more difficult for people to pay for the same amount but with much less data than before. Participant 4 states that "money to buy airtime and data to go on the internet is now depleting faster since I use work internet to perform many tasks online, and the money had not been budgeted for." It also seems like the purchase of airtime scratch cards is on the rise as participant 5 alludes to the fact that "data prices have sky rocketed, and also when I went to look for airtime I could not find it from those who sold it, in fact if I want to purchase airtime I have to paying using Ecocash and top up the actual amount with a dollar or two depending on the amount"

Due to electricity challenges being faced by the nation, many suburbs also face poor network due to power cuts. However, this still seems to be a challenge as four of the nine participants are struggling with network. Participants 4, 5, 6, and 9 all mentioned that network has been a challenge for them during this lockdown.

Despite the challenges the participants are facing they have also found themselves getting involved in other activities such has watching television, movies and series, listening to music, home workout plans, playing games on their mobile phones, gardening, reading, chatting and gaming with family members, social media advertising and learning new skills around the house.

\section{RECOMMENDATIONS}

- While awareness and publicity information on Covid19 is made available through the media, stress management tools should also be made available through the same channels of communication. This will assist people especially the youths with coping strategies in such trying times when people are gripped with anger, fear, panic and stress.

- Research studies should also focus on livelihoods of people in developing countries like Zimbabwe who are under lockdown on how they are coping with isolation as this can result in mental health related issues due to economic stress, depression and anxiety coming from media platforms on high death rates in developed countries.

- All media platforms have done much of the assistance in terms of communication although there is challenge in high data tariffs. The government should also provide communication support such as free data or other affordable ways of communication during the lock down as data has proven to be expensive for most youth and those in schools as students are required to learn online using data. 
Mazwi, N., Seremani, B., Kaseke, T., Lungu, C.

PSYCHO-SOCIAL EXPERIENCES OF YOUTHS DURING THE COVID-19 LOCKDOWN: INSIGHTS FROM HARARE,

ZIMBABWE

- Mental health awareness campaigns should be put in place to help youth see the positive sides of the COVID-19 and in order to reduce its psychological effects on the youth and people in general.

- There should be more studies conducted in the future that focus on the quantitative psychological effects of the COVID-19 lockdown on the youth's and people in general, social lives.

\section{CONCLUSIONS}

The COVID-19 Lockdown has brought its fair share of psychological effects that may present symptoms of mental health illness to the youths of Harare as evidenced in several responses where extroverted participants highlighted feelings of panic, anxiety, anger, depressed moods and stress as a result of uncertainty, freedom deprivation and prohibition of physical social contacts. These responses fulfilled the research objectives on psychological effects of the lockdown and the effect it had on social lives of youths. While different personalities reacted differently to the lockdown, the introverts embraced the social distancing and lockdown as they took time to rest from their busy schedules and some bonded with families in the comfort of their homes. In addition, the youths have also had socio-economic challenges due to the lockdown such as loss of income, failure to keep up with social networks due to inhibiting costs of data connections and network challenges. These highlights were in response to the research objective on how the youths responded to the lockdown. However not all research objectives were achieved as youths failed to highlight what would be done in future to improve their lives in similar situations of pandemic lockdowns. Limitations of the research is evidenced on the absence of respondents from youths who are students at universities or colleges and their experiences to the COVID-19 lockdown since all respondents were working youths. Further research must also be carried out on the impact of psychological interventions and access to mental health services that can be availed to youths during periods of epidemic lockdowns.

\section{REFERENCES}

Bowen, G.A. (2009). Document analysis as a qualitative research method. Qualitative research Journal, 9(2), 27-40. Doi: 103316/QRJ0902027.

Brooks S, Webster R, Smith L, Woodland L, Wessely S, Greenberg N \& Rubin J. (2020). The psychological impact of quarantine and how to reduce it: rapid review of the evidence. https:doi.org/10.1016/S0140-6736 (20)30460-8 (accessed 04 2020) 
Cheng V., Wong C., To K., Ho P., \& Yuen K. (2020). Preparedness and proactive infection control measures against the emerging coronavirus in China. Journal of hospital infections: 104 (3): 254255

International Federation of Red Cross and Red Crescent Societies (IFRC). (2020). Mental Health and Psychosocial Support for staff, volunteers and communities in an outbreak of novel coronavirus. IFRC: Hong Kong, 2020.

New Zealand: Ministry of Health. (2009). psychosocial impacts of quarantine and interventions that may help to relieve strain: Guidance notes. Ministry of Health: New Zealand.

Rosario L., Enrique M., Matias F., and Carlos R. (2020). Anxiety, worry and perceived stress in the world due to COVID-19 pandemic, March 2020. Preliminary results. Journal of MedRxiv. Retrieved April, 20, 2020, from https://doi.org/10.1101/2020.04.03.20043992.

Suedfeld, P., and Steel, D. (2000). The environmental psychology of capsule habitats. Journal of Annual Reviews Psychology 2000. 51(1): 227-253. www.annualreviews.org (accessed 04 2020).

Van Bortel T., Basnayake A., Wurie F., Jambai M., Koroma A., Muana A., Hann K., Eaton J., Martin S \& Nellums L. (2016). Psychosocial effects of an ebola outbreak at individual, community and international levels. Bulleting of World Health Organization; 94 (3): 210-214

Wang, C., Pan, R., Wan, X., Tan, Y., Xu, L., Ho, C. S., \& Ho, R. C. (2020). Immediate psychological responses and associated factors during the initial stage of the 2019 coronavirus disease (COVID19) epidemic among the general population in China. International journal of environmental research and public health, 17(5), 1729.

World Health Organisation. (2020). Mental health and psychosocial considerations during the COVID-19 outbreak. WHO/2019-nCoV/Mental Health/2020.1

Zhang, Y., \& Ma, Z. F. (2020). Impact of the COVID-19 Pandemic on Mental Health and Quality of Life among Local Residents in Liaoning Province, China: A Cross-Sectional Study. International Journal of Environmental Research and Public Health, 17(7), 2381.

ZIMSTAT/UNICEF. (2014). Multiple indicator cluster survey report. Retrieved April 5, 2020, from http://www.zimstat.co.zw/sites/default/files/img/publications/Mics\%202014/MICS_REPORT_2014.pd f. 